DE

M E D I C I N A

T R O P I C A L

$\mathrm{DE}$

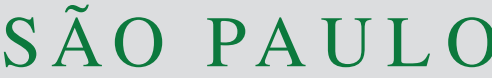

JOURNAL OF THE SÃO PAULO INSTITUTE OF TROPICAL MEDICINE

'Universidade Estadual de Maringá, Programa Ciências da Saúde, Maringá, Paraná, Brazil

${ }^{2}$ Universidade Estadual de Maringá, Curso de Farmácia, Maringá, Paraná, Brazil

${ }^{3}$ Universidade Estadual de Maringá, Curso de Enfermagem, Maringá, Paraná, Brazil

${ }^{4}$ Universidade Estadual de Maringá, Curso de Ciências Biológicas, Maringá, Paraná, Brazil

${ }^{5}$ Hospital Universitário Regional de Maringá, Maringá, Paraná, Brazil

Correspondence to: Fernanda Ferreira Evangelista

Universidade Estadual de Maringá, Programa Ciências da Saúde, Avenida Colombo, 5790, Bloco 126, Zona 7, CEP 87020-900, Maringá, PR, Brazil Tel: +55 44999125511

E-mail: fer.evangelista@ hotmail.com

Received: 9 November 2019

Accepted: 18 June 2020

\section{Prospective evalution of pregnant women with suspected acute toxoplasmosis treated in a reference prenatal care clinic at a university teaching hospital in Southern Brazil}

\author{
Fernanda Ferreira Evangelista ${ }^{(1)}$, Francini Martini Mantelo ${ }^{(2}$, Keller Karla \\ de Lima ${ }^{3}$, Ariella Andrade Marchioro', Lucimara Fátima Beletini', Amanda \\ Hinobu de Souza4, Priscila Laet Santana1, Cristiane de Oliveira Riedo', \\ Lourenço Tsunetomi Higa ${ }^{5}$, Ana Lúcia Falavigna Guilherme ${ }^{1}$
}

\section{ABSTRACT}

Infection by the protozoan Toxoplasma gondii during pregnancy demands greater attention from the health authorities due to the risk of placental transmission, which can have devastating consequences to the foetus and newborn. This study was conducted in a high-risk prenatal care outpatient clinic of a university teaching hospital. Pregnant women screened for specific IgM and IgG anti-T. gondii, attended from January 2009 to August 2018 were included. From 530 suspected patients, 218 were followed up and they presented positive IgM and IgG anti-T. gondii. From these patients, 83 (38.0\%) had low IgG avidity, 39 (18\%) seroconverted in the second or third trimester of pregnancy, 19 (8.7\%) had no avidity test, 69 $(31.6 \%)$ had high IgG avidity after 16 weeks of gestation, five had recurrent chorioretinitis $(2.2 \%)$ and three $(1.3 \%)$ were seropositive to HIV. Complementary diagnoses were made in $30 / 48(62.5 \%)$ of the patients revealing the presence of specific IgA antibodies raised to T. gondii; 3/63 (4.8\%) peripheral blood samples and 1/57 (1.8\%) amniotic fluid sample. There were eight foetal deaths, one case of neonatal hepatomegaly and one case of $T$. gondii DNA detected in a peripheral blood sample. Of the 139 newborn deliveries at the teaching hospital, there was a $38 \%$ loss of follow-up. The prevalence of congenital toxoplasmosis was 1.2 cases/1,000 live births in this study area, according to the retrospective survey of cases. Prenatal treatment may have helped to reduce the risk of vertical transmission.

KEYWORDS: Toxoplasma gondii. Congenital toxoplasmosis. Serological diagnosis. Amniotic fluid. Prenatal care.

\section{INTRODUCTION}

Infection by the protozoan Toxoplasma gondii during pregnancy demands greater attention from the health authorities due to the risk of placental transmission, which can have devastating consequences to the foetus and newborn ${ }^{1}$. The outcome of congenital transmission is influenced by factors such as $T$. gondii genotype, strain virulence, inoculum size, maternal immune status, maternal parasitaemia, gestational age at the time of infection and prenatal treatment ${ }^{2,3}$. Infections tend to be more severe in the first weeks of gestation due to the ontogenetic development of the foetus, and 20\% of infected conceptions may present important clinical signs such as central nervous system injuries ${ }^{4}$ or even intrauterine death ${ }^{5}$. Furthermore, the risk of foetal transmission increases significantly as gestational age progresses, ranging from $4.5-17 \%$ in the first trimester to $65-75 \%$ in the third trimester ${ }^{4,6}$. If transmission 
occurs in the third trimester, neurological lesions may be absent but some infected newborns present with subclinical infection and they are at risk of developing ocular lesions at any time ${ }^{4,5}$. In South America, 70-80\% of children infected in the second and third gestational trimesters frequently develop important classical or atypical recurrent eye injury as a result of chorioretinitis ${ }^{7,8}$. This fact is attributed to the parasite genotypic diversity present in this region, including clonal lineages with high virulence $e^{9,10-12}$.

Treatment of pregnant women aims to prevent the transplacental transmission or to treat the infected foetus, reducing the sequelae ${ }^{13}$. Only $30 \%$ of maternal infections induce clinical manifestations, which are suggestive of acute toxoplasmosis. The diagnosis is based on regular serological tests in susceptible pregnant women, and acute infection can be recognized when there is seroconversion. In the absence of previous serological results this diagnosis may be difficult ${ }^{14}$ and complementary tests are therefore important tools for the diagnostic accuracy. However, these tests represent significant costs and are not always available in developing countries such as Brazil. A prenatal rapid and efficient diagnosis enables prompt and adequate treatment ${ }^{14}$. Although there is no definitive gold standard treatment for $T$. gondii infection and the medications available are not fully effective ${ }^{15}$, numerous reports in the literature suggest that the treatment of acute toxoplasmosis during pregnancy reduces the risk of foetal infection and sequelae $e^{1,14,16,17}$. Spiramycin is a macrolide antibiotic used to prevent transmission to the foetus that reaches elevated concentrations in the placenta but does not readily cross it. A combination of sulfadiazine, pyrimethamine and folinic acid (SPFA) is the alternative treatment in confirmed or highly suspected foetal infections that can reduce the severity of foetal disease. This drug should not be used in the first trimester because it is potentially teratogenic ${ }^{18}$. An earlier diagnosis of acute toxoplasmosis in pregnant women is therefore essential for adequate interventions, so the aim of this study was to prospectively evaluate pregnant women with suspected acute toxoplasmosis attending a high-risk prenatal care referral service in Southern Brazil.

\section{METHODS}

\section{Study population}

This study included all the pregnant women with suspected acute toxoplasmosis with positive $\operatorname{IgM}$ and $\operatorname{IgG}$ anti-T. gondii and pregnant women with HIV and positive $\mathrm{IgG}$ anti-T. gondii that were referred to the high-risk prenatal care outpatient clinic of the University Hospital of Maringa, State University of Maringa (HUM/UEM). The patients firstly attended Basic Health Units (BHUs) from the $15^{\text {th }}$ Regional Department of Public Health (15 $\left.{ }^{\text {th }} \mathrm{RH}\right)$, which assist patients from 30 municipalities in the Northwestern region of Parana State, Southern Brazil, with a population of approximately 800,000 inhabitants $^{19}$ (Figure 1). Pregnant women with a high IgG avidity test in the first trimester of gestation were excluded from the study, leaving only those with positive IgM or positive $\mathrm{IgM} / \mathrm{IgG}$ since previous gestations.

The study was conducted from January 2009 to August 2018. The study was approved by the Ethics and Research Committee of the State University of Maringa (CAAE No 56308816.4.0000.0104 and 11911612.0.0000.5220).

\section{Detection of IgM and IgG antibodies anti-T. gondii}

The first serological tests were performed during prenatal care at the BHUs, according to the criteria of the toxoplasmosis manual of the Health Secretary of Parana State $^{20}$ : chemiluminescent microparticle immunoassay (CMIA) using ARCHITECT Toxo IgG ${ }^{\mathrm{TM}}$ and ARCHITECT Toxo IgM ${ }^{\mathrm{TM}}$ kits, according to the manufacturer's specifications (Abbott, Wiesbaden, Germany). The ARCHITECT Toxo IgG assay is a CMIA for determination of the avidity of $\mathrm{IgG}$ antibodies to T. gondii in human serum and plasma samples ${ }^{20,21}$. The calculation of the avidity percentage allowed to classify the samples into groups of low $(<50.0 \%)$ or high $(\geq 60 \%)$ avidity ${ }^{21}$. According to this manual, pregnant women considered in the acute phase of the infection show positive IgM and IgG and a low IgG avidity test, or high avidity test when $>16$ weeks of pregnancy. Seronegative patients should receive more attention and repeat tests every trimester.

\section{Complementary diagnosis}

When the standard serological tests had inconclusive results, other confirmatory exams were requested by the specialized service, including the anti-T. gondii IgA serological test, performed by the enzyme-linked immunosorbent assay (ELISA) method (reference values: $<0.80$, negative; $>1.10$, positive) from an outsourced service. Tests for detection of $T$. gondii DNA in peripheral blood and amniotic fluid samples, as well as inoculation in animals, were performed, in some cases, by the Parasitology Laboratory, State University of Maringa.

Polymerase chain reaction (PCR) amplifications were performed with DNA extracted from amniotic fluid and peripheral blood samples by using the commercial kit Purelink $^{\circledR}$ (Thermo Fisher Scientific, Waltham, USA), with primers from the B1 gene and Toxo 4-5); and samples were also intraperitoneally inoculated in mice ${ }^{22}$. 

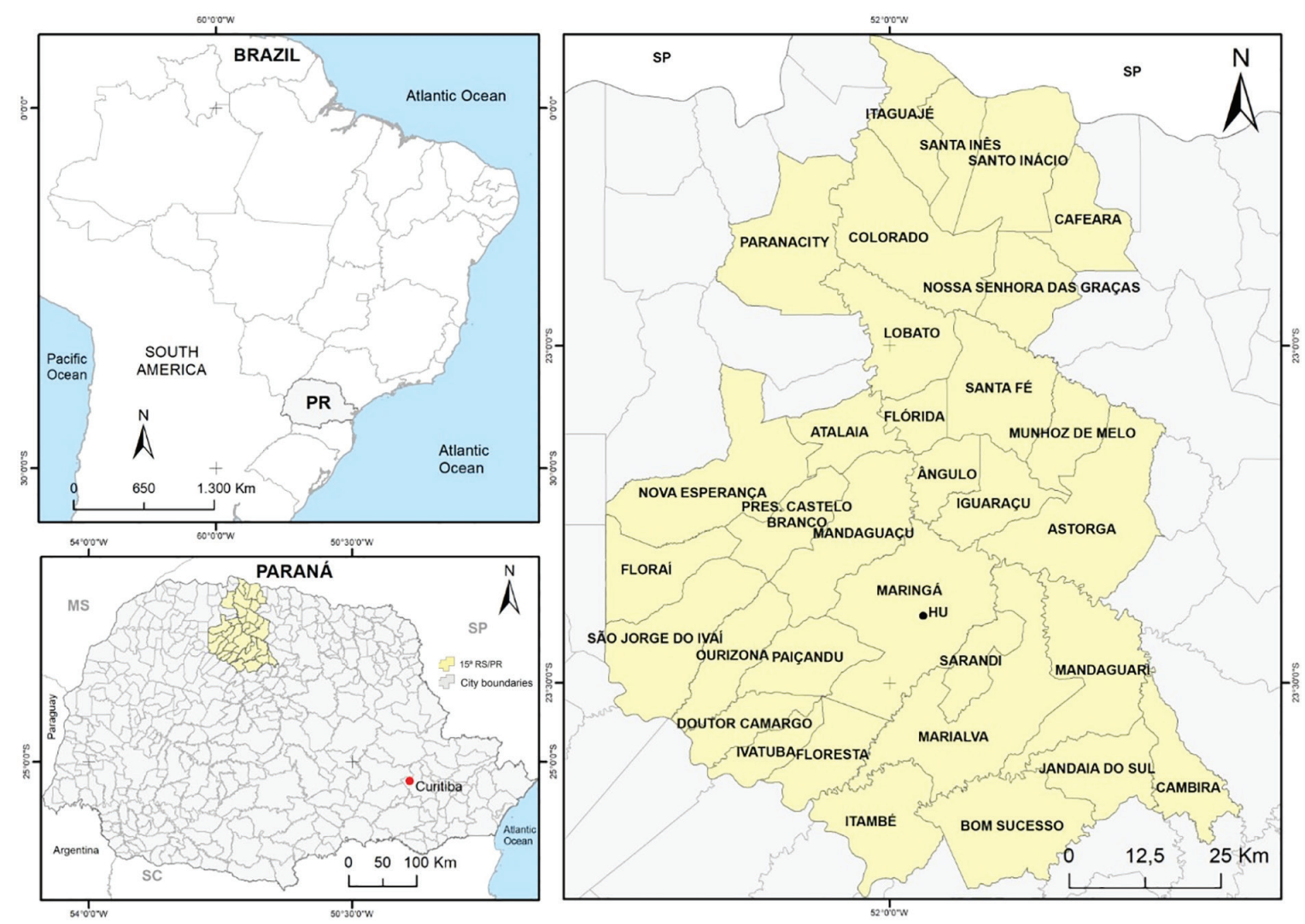

Figure 1 - Geographic representation of pregnant women attended at the HU/UEM high risk pregnancy outpatient clinic.

T. gondii DNA genotyping was carried out on amniotic fluid and blood samples from pregnant women or mice specimens using the genetic markers SAG1, 5'-3'SAG2, alt. SAG2, SAG3, BTUB, GRA6, c22-8, c29-2, L358, PK1 and Apico. Strains GT1, PTG, CTG, TgCgCa1, MAS, TgCatBr5 and $\mathrm{TgCatBr64}$ were used as standards ${ }^{23}$. The target DNA sequences were amplified by multiplex-PCR with external primers for all the markers, followed by nested-PCR using internal primers for each marker individually. The results were compared and ranked according to the ToxoDB database (http://toxodb.org/toxo/).

The animal experiments were approved by the Ethical Committee for Animal Use of the State University of Maringa (CEUA/UEM No 036/2009 and 5654290317, 2017).

All pregnant women (including confirmed or suspected cases) underwent imaging diagnosis and they were monitored monthly until the end of gestation by ultrasonography (EnVisor HD with high-definition convex probe, 2-5 MHz; Philips EnVisor, Riverside, CA, USA).

\section{Treatment of pregnant women with toxoplasmosis}

In the high-risk prenatal care outpatient clinic of the HUM/UEM, all the pregnant women with positive IgM and
IgG anti-T.gondii and low avidity or with positive IgM and IgG anti-T.gondii in the last two trimesters were treated ${ }^{20}$. Spiramycin is initially prescribed when maternal infection is diagnosed in the first trimester (positive $\operatorname{IgM}$ and $\operatorname{IgG}$ anti-T.gondii with low $\mathrm{IgG}$ avidity) and after 34 weeks of gestation. From 16 to 34 weeks of gestation, the women were treated with the triple combination of $\mathrm{SPFA}^{20}$.

\section{RESULTS}

Among 3,168 women referred to the high-risk prenatal care clinic at the HUM/UEM during the study period, 530 were suspected of acute toxoplasmosis. However, only 218 (6.9\%) were included in the follow-up.

Of the 218 pregnant women included in the sample, 122 (3.85\% of 3,168 pregnant women attended at the unit) were confirmed as having acute toxoplasmosis, 83 with low IgG avidity and 39 with seroconversion during the gestational period (Figure 2). For the remaining, 88 had inconclusive diagnoses, 69 due to high IgG avidity after 16 weeks' gestation and 19 referred from the HUM/UEM by the BHU without an IgG avidity test (Figure 3), and there were also five cases with recurrent chorioretinitis $(2 \%)$ and three cases $(1.3 \%)$ who were HIV-positive and were positive to IgG anti-T. gondii. 


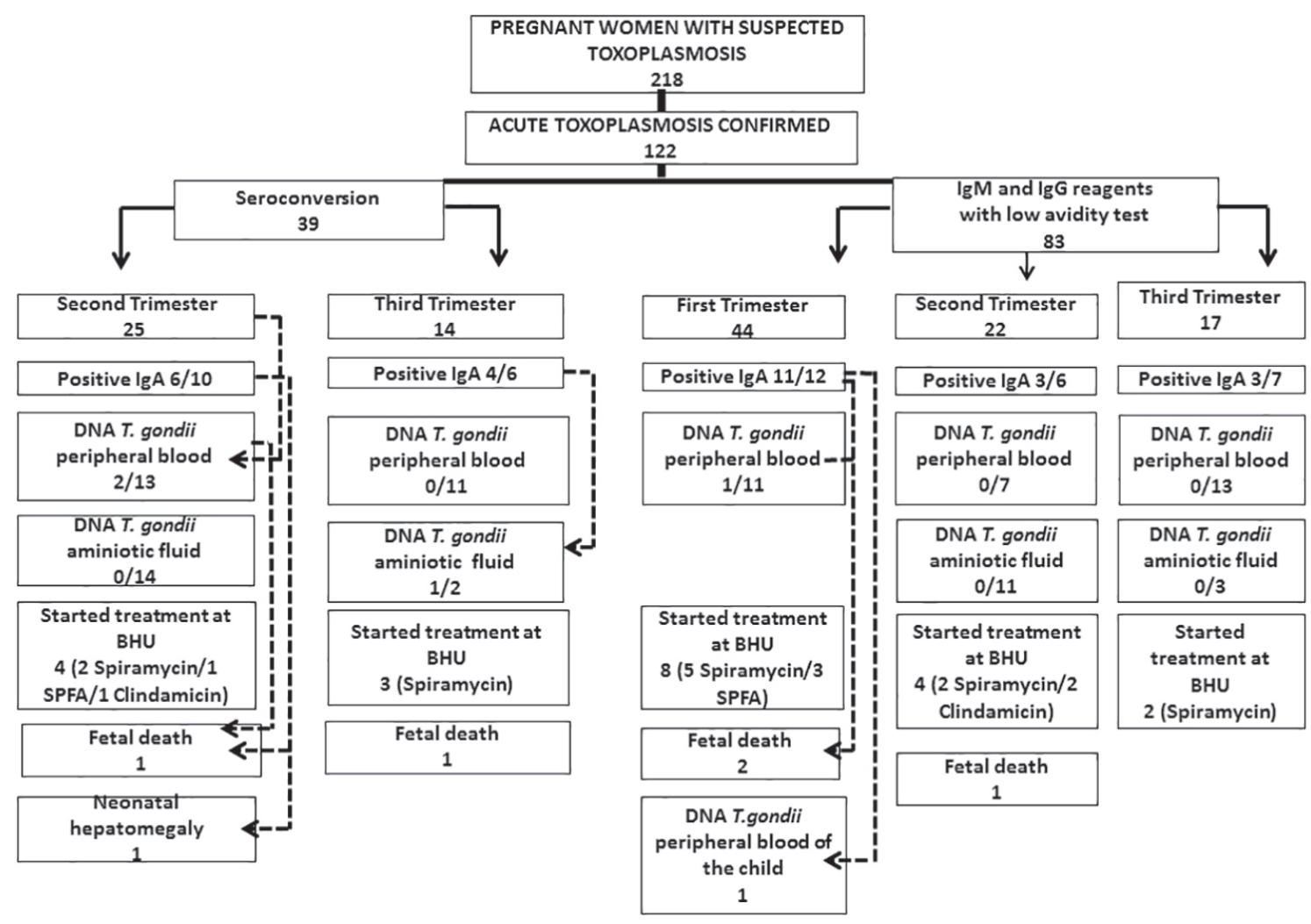

Figure 2 - Cases confirmed in acute phase of toxoplasmosis in pregnant women attended at the high risk ambulatory of the HUM/ UEM from January 2009 to August 2018, Southern Brazil.

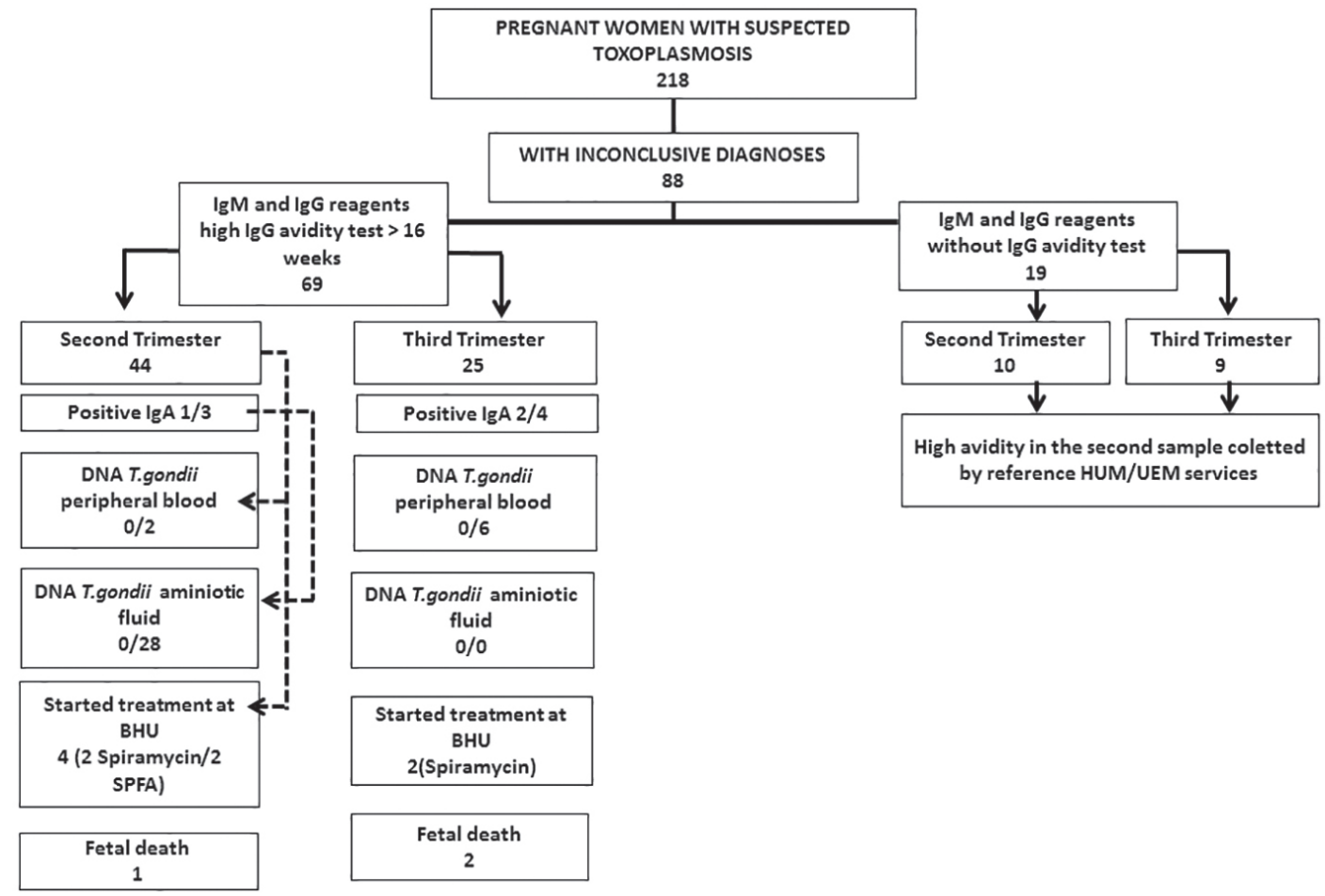

Figure 3 - Pregnant women referred to the high risk outpatient clinic of HUM/UEM with inconclusive diagnoses in relation to acute toxoplasmosis, from January 2009 to august 2018, Southern Brazil 
Prospective evalution of pregnant women with suspected acute toxoplasmosis treated in a reference prenatal care clinic

Table 1 - Profile of Toxoplasma gondii genotypic markers from peripheral blood samples of pregnant women in Parana State, Brazil

\begin{tabular}{lccccccccccc}
\hline Sample & SAG1 & 5SAG2/3SAG2 & ALT SAG2 & SAG3 & BTUB & GRA6 & C22-8 & C29-2 & L358 & PK1 & APICO \\
\hline TgCTBrcz & na & III & u-1 & III & III & II & I & na & na & na & I \\
TgCTBrkz & na & I & II & III & । & I & u-2 & II & na & II & । \\
\hline
\end{tabular}

${ }^{*}$ na $=$ not amplified.

Among the 83 pregnant women referred with low IgG avidity (Figure 2) there were three foetal deaths, including one case with $T$. gondii DNA detected in peripheral blood and positive to $\operatorname{IgA}$ anti-T. gondii. There was one case with T. gondii DNA detected in the newborns's peripheral blood three days after birth and the pregnant woman was positive to IgAanti-T. gondii. None of the 14 amniotic fluid samples from this group showed $T$. gondii DNA or tachyzoites in mice (Figure 2).

Of the 39 pregnant women with seroconversion, 10/16 (63\%) were also positive to IgA anti-T. gondii (Figure 2) and $T$. gondii DNA was detected in two $(8.3 \%)$ peripheral blood samples that were partially genotyped (Table 1). In this soroconversion group there were also two (second and third trimester) foetal deaths and one newborn with hepatomegaly and treated with SPFA (Figure 2).

Ultrasound images revealed only $2 / 218$ cases with alterations, one with holoprosencephaly and another fetus showing intrauterine growth restriction.

Among the 69 pregnant women with high IgG avidity but no prenatal care in the first trimester of pregnancy (Figure 3), there were two foetal deaths in the third trimester and $\operatorname{IgA}$ was positive in three out of seven investigated (43\%). Nineteen pregnant women were referred without an IgG avidity test, which was carried out later in the high-risk prenatal outpatient clinic (Figure 3).

Regarding maternal treatment, 27/218 (12\%) were referred to the HUM/UEM using medication, mainly spiramycin (Figures 2 and 3). In the HUM/UEM, 38 were treated with spiramycin until 16 weeks of gestation, with SPFA for $>16-34$ weeks and with spiramycin until the end of gestation; 53 pregnant women started or continued with SPFA, being replaced by spiramycin after 34 weeks. The treatment was maintained with spiramycin in 127 (58\%) pregnant women, including those who underwent amniocentesis and PCR to T. gondii were negative (Figures 2 and 3).

Adverse effects of treatment with SPFA were observed in 46/91 (50.5\%) pregnant women, presenting as vomiting, headache and stomachache, with five cases of severe maculopapular rashes. Among the 210 pregnant women who had live births, 139 (66\%) were born in the HUM/ UEM.

\section{DISCUSSION}

This study is a follow-up of almost 10 years on pregnant women diagnosed with acute toxoplasmosis and aimed to contribute to the understanding of human infections by T. gondii in the Northwestern of Parana State, South of Brazil. There are few prospective studies in this region that have evaluated clinical, laboratory and treatment aspects in a follow-up of pregnant women with acute toxoplasmosis. However, the difficulties of diagnosis, for various reasons, associated with the scarcity of resources in the country, have not always enabled a full investigation of the cases.

Considering the 122 pregnant woman with confirmed diagnosis, including seroconversion and low $\operatorname{IgG}$ avidity, the prevalence of acute gestational toxoplasmosis was 1.21 cases per 1,000 live births in the $15^{\text {th }} \mathrm{RH}$ of Parana State (there were 100,656 live births in this region during the period $)^{24}$. Another State of Southern Brazil found a lower prevalence of 0.57 cases per 1,000 live births ${ }^{25}$. If we consider the number of pregnant women attended at the unit (3168) during the period of the study, the prevalence was $3.85 \%$. This percentage is well above that found in the USA, which is $0.2-1 \%{ }^{18}$. In South America, studies have shown variable prevalences of acute infections during pregnancy $(0.48-5.3 \%)^{25-27}$. This demonstrates the urgent need to implement accurate and rapid diagnosis, as well as efforts aimed at sanitary structure implementation and food education in developing countries. In addition, it has been shown that the screening of seronegative pregnant women is cost-saving, especially in regions with a high prevalence of the infection ${ }^{14,28}$. During the last few years, the general seroprevalence of toxoplasmosis has declined in developed countries but this is not the reality in some developing countries, where seroprevalence remains stable or even increased ${ }^{25}$. Countries with high seroprevalence in the general population also had high rates of acute infection in pregnant women ${ }^{28}$.

In addition, it was not possible to conclude the diagnosis in several cases of this study. In Brazil, although serological screening for acute toxoplasmosis is recommended in the prenatal screening, considering the high prevalence of this zoonosis ${ }^{29}$, difficulties compromising the diagnosis are frequently faced. The reasons include late prenatal evaluation, serological tests being available only twice 
during gestation for IgM/IgG-negative pregnant women, high cost of complementary diagnostic methods, logistics and difficulty accessing services in different geographical regions. Throughout this study, other efforts have been developed such as an educational action between health professionals and pregnant women, adding to the support of this reference center in gestational toxoplasmosis, with the aim of increasing control of this zoonosis ${ }^{30-33}$.

The serological IgA test was performed in a minority of cases due to restricted financial resources, which can be considered a limitation of this study, but the test indicates a correlation with the $66 \%$ of pregnant women with low IgG avidity, including cases of foetal deaths and the presence of T. gondii DNA in blood or amniotic fluid samples. The IgA anti-T. gondii test may be an important tool to confirm acute infections, considering that the avidity of $\mathrm{IgG}$ in some cases remains low for prolonged periods ${ }^{34}$. Although IgA testing may be useful for confirming an inconclusive diagnosis, in some cases it is not available in public health services.

The molecular evidence of $T$. gondii in peripheral blood and amniotic fluid samples is a useful tool for confirming the diagnosis, but detection depends on a minimum burden of tachyzoites, which is influenced by the time of infection ${ }^{11}$. The probability is higher when the time of infection is known. Two cases of $T$. gondii DNA were detected, one in peripheral blood and one in the amniotic fluid sample. Most of the pregnant women did not agree with amniocentesis and amniotic fluid collection. It should be noted that this technique requires specialized equipment and the correct laboratory and hospital infrastructure, which is not the reality in developing countries.

It was possible to determine only partial genotypes because only a small amount of DNA was recovered in the samples, however it was possible to observe differences in some loci. In South America, there are countless nonarchetypal genotypes ${ }^{2,10,11,20}$. Parasite genotypes seem to play a role in the virulence of human infections ${ }^{14}$, and it was demonstrated that a higher prevalence of non-archetypal T. gondii strains increase the risk of ocular manifestations of the disease ${ }^{35}$. Sanders $e$ al. $^{8}$, in the same study area, reported learning difficulties and high ocular impairment in children who were infected in the third trimester of pregnancy. These facts contributed to the finding in the present study of pregnant women with recurrent retinochoroiditis and impaired immune systems.

Although fetal ultrasound analyses are routinely used as an additional diagnostic instrument to detect vertical transmission and to perform the foetal follow-up, only one case of foetal death revealed previous alterations. Similarly, Boudaouara et al..$^{36}$ found no morphological abnormalities in ultrasound examinations of foetuses with congenital toxoplasmosis.

Determining the most likely period of infection can be challenging when the woman's referral does not occur in early pregnancy/infection. In most cases, it was not possible to determine precisely the time of infection, except in 39 pregnant women with seroconversion and in 35 with low avidity and reactive $\operatorname{IgA}$ in the first trimester. Spiramycin was the most widely used drug during pregnancies, although almost half of the pregnant women also used SPFA at other times, especially in late diagnoses or seroconversions. Studies demonstrated that the incidence of congenital toxoplasmosis with the use of the triple combination of SPFA was lower than with spiramycin, although there was no statistical difference $^{37,38}$. In the present study, in $5 / 8$ cases of foetal deaths the pregnant woman was treated with spiramycin. The early diagnosis of maternal infection and an earlier treatment contributed to reduce the risk of foetal infection and sequelae ${ }^{14}$, with a reduction of cerebral calcifications when treatment was given within four weeks after maternal infection ${ }^{39}$. The prenatal treatment reduces the risk of mother-to-child transmission when compared to those without treatment ${ }^{29}$. Although these regimens are recommended in several countries, there is no consensus on the effectiveness of therapy for blocking transmission or for the treatment of congenital toxoplasmosis ${ }^{40}$.

The high occurrence of adverse effects observed $(50.5 \%)$ is an obstacle to the treatment of pregnant women. Considering that the gestational treatment has a substantial impact on the infants protection ${ }^{17,41}$, the earliest diagnosis and correct treatment must be prioritized. In Brazil, susceptible pregnant women (negative serology) must have at least three serologies performed during pregnancy, according to the recommendation of the guidelines of the Ministry of Health ${ }^{42}$. However, experiences in other countries show that in women in whom the infection is identified and treated early, the greater the effectiveness in reducing fetal infection, or even reducing the severity of the manifestations in the infant ${ }^{41,43}$. Quite similar findings were found in a Brazilian research that demonstrated that children born to treated women tend to be asymptomatic ${ }^{44}$. Therefore, monthly serology for susceptible women (IgM and $\operatorname{IgG}$ anti- $T$. gondii negative) should be considered in regions with a high prevalence of toxoplasmosis ${ }^{45,46}$.

Unfortunately, in this study, another limitation was that it was not possible to follow up $57.6 \%$ of the infants. For this reason, an upgrade was carried out for health professionals at the $15^{\text {th }} \mathrm{RH}$ Department of Parana to better serve these cases of suspected acute infection and care for susceptible pregnant women. 


\section{CONCLUSIONS}

This study demonstrated a relevant prevalence of acute toxoplasmosis during pregnancy in this region. Although restricted to a state of the southern region, it is extremely important for understanding the incidence of congenital disease in the region, providing perspectives for future multicenter studies to evaluate the real incidence of congenital toxoplasmosis in Brazil. However, the detection of seroconversion during pregnancy occurred in a minority of cases, even though it is a reference center for toxoplasmosis in Brazil. Failures in the early referral of pregnant women under suspicion of acute infections and a lack of follow-up of the majority of newborns can induce failures in the diagnosis of acute toxoplasmosis in pregnancy, as well as of congenital toxoplasmosis. The combination of several techniques, including anti-T. gondii $\operatorname{IgA}$ testing and protozoan DNA screening, increases the diagnostic accuracy. However, the implementation of modern diagnostic techniques can raise costs for the public health system. The monthly serology of non-reactive pregnant women to $T$. gondii is a fundamental control mechanism, especially in developing countries with a high prevalence of toxoplasmosis and genotypic diversity of the parasite.

\section{ACKNOWLEDGMENTS}

We thank the teachers, technicians, and trainees of the Parasitology Department and sincere thanks to all the staff and the Nurses of the University Hospital of Maringa for the care of pregnant women and we thank the pregnant women who agreed to participate in our study because without them this work would not be possible. We thank Wesley Ferreira for building the map. This study was funded by the Coordination of Improvement of Higher Education Personnel (CAPES)

\section{AUTHORS' CONTRIBUTIONS}

Study design (FFE, PLS, ALFG); data collection (FFE, FMM, KKL, AHS, COR, AAM); data analysis (FFE, ALFG, PLS, LTH); development of initial draft manuscript (FFE, ALFG, PLS, AHS, COR), study supervision (ALFG, PLS, FFE). All authors reviewed and approved the final draft of manuscript.

\section{FUNDING}

This study was funded by the Coordination of Improvement of Higher Education Personnel (CAPES).

\section{REFERENCES}

1. Robert-Gangneux F, Dardé ML. Epidemiology of and diagnostic strategies for toxoplasmosis. Clin Microbiol Rev. 2012;25:26496.

2. Carneiro AC, Andrade GM, Costa JG, Pinheiro BV, VasconcelosSantos DV, Ferreira AM, et al. Genetic characterization of Toxoplasma gondii revealed highly diverse genotypes for isolates from newborns with congenital toxoplasmosis in Southeastern Brazil. J Clin Microbiol. 2013;51:901-7.

3. Kravetz J. Congenital toxoplasmosis. BMJ Clin Evid. 2013;2013:0906.

4. Silva LR, Okazaki EL. Enfermagem e a prevenção da Toxoplasmose durante a gestação. Rev Enferm UNISA. 2012;13:43-7.

5. Wilson C, Nizet V, Maldonado Y, Remington J, Klein J. Remington and Klein's Infectious diseases of the fetus and newborn infant. $8^{\text {th }}$ ed. Philadelphia: Elsevier Saunders; 2015.

6. Avelar JB, Silva MG, Rezende HH, Storchilo HR, Amaral WN, Xavier IR, et al. Epidemiological factors associated with Toxoplasma gondii infection in postpartum women treated in the public healthcare system of Goiânia, State of Goiás, Brazil. Rev Soc Bras Med Trop. 2018;51:57-62.

7. Melamed J, Eckert GU, Spadoni VS, Lago EG, Uberti F. Ocular manifestations of congenital toxoplasmosis. Eye (Lond). 2010;24:528-34.

8. Sanders AP, Santos T, Felipe CK, Estevão ML, Cícero C, Evangelista F, et al. Ocular lesions in congenital toxoplasmosis in Santa Isabel do Ivaí, Paraná, Brazil. Pediatr Infect Dis J. 2017;36:817-20.

9. Carneiro BF, Miranda MM, Silveira-Neto OJ, Linhares GF, Araujo LB. Inquérito sorológico para Toxoplasma gondii em mamíferos neotropicais mantidos no centro de triagem de animais silvestres, Goiânia, Goiás. Rev Patol Trop. 2014;43:69-78.

10. Grigg ME, Dubey JP, Nussenblatt RB. Ocular toxoplasmosis: lessons from Brazil. Am J Ophthalmol. 2015;159:999-1001.

11. Pardini L, Bernstein M, Carral LA, Kaufer FJ, Dellarupe A, Gos ML, et al. Congenital human toxoplasmosis caused by nonclonal Toxoplasma gondii genotypes in Argentina. Parasitol Int. 2019;68:48-52.

12. Pena HF, Gennari SM, Dubey JP, Su C. Population structure and mouse-virulence of Toxoplasma gondii in Brazil. Int $\mathrm{J}$ Parasitol. 2008;38:561-9.

13. Antczak M, Dzitko K, Długońska H. Human toxoplasmosis: searching for novel chemotherapeutics. Biomed Pharmacother. 2016;82:677-84.

14. Wallon M, Peyron F. Congenital toxoplasmosis: a plea for a neglected disease. Pathogens. 2018;7:25.

15. Wei HX, Wei SS, Lindsay DS, Peng HJ. A systematic review and meta-analysis of the efficacy of anti-Toxoplasma gondii medicines in humans. PLoS One. 2015;10:e0138204. 
16. Prusa AR, Kasper DC, Sawers L, Walter E, Hayde M, Stillwaggon E. Congenital toxoplasmosis in Austria: prenatal screening for prevention is cost-saving. PLoS Negl Trop Dis. 2017;11:e0005648.

17. Cortina-Borja M, Tan HK, Wallon M, Paul M, Prusa A, Buffolano $\mathrm{W}$, et al. Prenatal treatment for serious neurological sequelae of congenital toxoplasmosis: an observational prospective cohort study. PLoS Med. 2010;7:e1000351.

18. Moncada PA, Montoya JG. Toxoplasmosis in the fetus and newborn: an update on prevalence, diagnosis and treatment. Expert Rev Anti Infect Ther. 2012;10:815-28.

19. Instituto Brasileiro de Geografia e Estatística. Estimativas da população residente para os municípios e para as unidades da federação brasileiros com data de referência em $1^{\circ}$ de julho de 2019. Rio de Janeiro; IBGE: 2019. [cited 2020 Jun 19]. Available from: https://agenciadenoticias.ibge.gov.br/media/ com_mediaibge/arquivos/42ff76cf13a382a709c1ba1421 4b8612.pdf

20. Paraná. Secretaria da Saúde. Atenção ao pré-natal: caderno de atenção ao pré-natal: toxoplasmose. Curitiba: Secretaria da Saúde; 2014.

21. Gay-Andrieu F, Fricker-Hidalgo H, Sickinger E, Espern A, Brenier-Pinchart MP, Braun HB, et al. Comparative evaluation of the ARCHITECT Toxo IgG, IgM, and IgG Avidity assays for anti-Toxoplasma antibodies detection in pregnant women sera. Diagn Microbiol Infect Dis. 2009;65:279-87.

22. Higa LT, Garcia JL, Su C, Rossini RC, Falavigna-Guilherme AL.Toxoplasma gondii genotypes isolated from pregnant women with follow-up of infected children in southern Brazil. Trans R Soc Trop Med Hyg. 2014;108:244-6.

23. Su C, Shwab EK, Zhou P, Zhu XQ, Dubey JP. Moving towards an integrated approach to molecular detection and identification of Toxoplasma gondii. Parasitology. 2010;137:1-11.

24. Brasil. Ministério da Saúde. DATASUS: nascidos vivos - Brasil. [cited 2020 Jun 19]. Available from: http://tabnet.datasus.gov. br/cgi/deftohtm.exe?sinasc/cnv/nvuf.def

25. Lovison R, Rodrigues RM. Incidência e prevalência da toxoplasmose na região Sul do Brasil: revisão bibliográfica. Rev Saude Publica Santa Catarina. 2017;10:61-75.

26. Silva MG, Câmara JT, Vinaud MC, Castro AM. Epidemiological factors associated with seropositivity for toxoplasmosis in pregnant women from Gurupi, State of Tocantins, Brazil. Rev Soc Bras Med Trop. 2014;47:469-75.

27. Rosso F, Les JT, Agudelo A, Villalobos C, Chaves JA, Tunubala GA, et al. Prevalence of infection with Toxoplasma gondii among pregnant women in Cali, Colombia, South America. Am J Trop Med Hyg. 2008;78:504-8.

28. Varella IS, Wagner MB, Darela AC, Nunes LM, Müller RW. Prevalência de soropositividade para toxoplasmose em gestantes. J. Pediatr (Rio J). 2003;79:69-74.

29. Prusa AR, Kasper DC, Pollak A, Gleiss A, Waldhoer T, Hayde M.
The Austrian Toxoplasmosis Register, 1992-2008. Clin Infect Dis. 2015;60:e4-10.

30. Brasil. Ministério da Saúde. Secretaria de Atenção à Saúde. Departamento de Ações Programáticas Estratégicas. Gestação de alto risco: manual técnico. $5^{\mathrm{a}}$ ed. Brasilia: Ministério da Saúde; 2012. [cited 2020 Jun 19]. Available from: http://bvsms. saude.gov.br/bvs/publicacoes/manual_tecnico_gestacao_alto_ risco.pdf

31. Branco BH, Araujo SM, Falavigna-Guilherme AL. Prevenção primária da toxoplasmose: conhecimento e atitudes de profissionais de saúde e gestantes do serviço público de Maringá, Paraná. Sci Med (Porto Alegre). 2012;22:185-90.

32. Contiero-Toninato AP, Cavalli HO, Marchioro AA, Ferreira EC, Caniatti MC, Mitsuka-Breganó R, et al. Toxoplasmosis: an examination of knowledge among health professionals and pregnant women in a municipality of the State of Paraná. Rev Soc Bras Med Trop. 2014;47:198-203.

33. Evangelista FF, Riedo CO, Higa LT, Marchioro AA, FalavignaGuilherme AL. Análise do controle da toxoplasmose gestacional e ocular nos serviços de atenção primária da 15ª Regional de Saúde do Paraná. Espac Saude. 2017;18:39-44.

34. Higa LT, Araújo SM, Tsuneto L, Castilho- Pelloso M, Garcia JL, Santana RG, et al. A prospective study of Toxoplasma-positive pregnant women in southern Brazil: a health alert. Trans R Soc Trop Med Hyg. 2010;104:400-5.

35. Khan A, Jordan C, Muccioli C, Vallochi AL, Rizzo LV, Belfort $\mathrm{Jr} \mathrm{R}$, et al. Genetic divergence of Toxoplasma gondii strains associated with ocular toxoplasmosis, Brazil. Emerg Infect Dis. 2006;12:942-9.

36. Boudaouara Y, Aoun K, Maatoug R, Souissi O, Bouratbine A, Abdallah RB, et al. Congenital toxoplasmosis in Tunisia: prenatal and neonatal diagnosis and postnatal follow-up of 35 cases. Am J Trop Med Hyg. 2018;98:1722-6.

37. Findal G, Stray-Pedersen B, Holter EK, Berge T, Jenum PA. Persistent low Toxoplasma IgG avidity is common in pregnancy: experience from antenatal testing in Norway. PLoS One. 2015;10:e0145519.

38. Mandelbrot L, Kieffer F, Sitta R, Laurichesse-Delmas H, Winer $\mathrm{N}$, Mesnard L, et al. Prenatal therapy with pyrimethamine + sulfadiazine vs spiramycin to reduce placental transmission of toxoplasmosis: a multicenter, randomized trial. Am J Obstet Gynecol. 2018;219:386.e1-9.

39. Gras L, Wallon M, Pollak A, Cortina-Borja M, Evengard B, Hayde $\mathrm{M}$, et al. Association between prenatal treatment and clinical manifestations of congenital toxoplasmosis in infancy: a cohort study in 13 European centres. Acta Paediatr. 2005;94:1721-31.

40. Dunay IR, Gajurel K, Dhakal R, Liesenfeld O, Montoya JG. Treatment of toxoplasmosis: historical perspective, animal models, and current clinical practice. Clin Microbiol Rev. 2018;31:e00057-17.

41. Wallon M, Peyron F, Cornu C, Vinault S, Abrahamowicz M, 
Bonithon Kopp C, et al. Congenital Toxoplasma infection: monthly prenatal screening decreases transmission rate and improves clinical outcome at age 3 years. Clin Infect Dis. 2013;56:1223-31.

42. Brasil. Ministério da Saúde. Secretaria de Vigilância em Saúde. Departamento de Vigilância das Doenças Transmissíveis. Protocolo de notificação e investigação: toxoplasmose gestacional e congênita. Brasília: Ministério da Saúde, 2018. [cited 2020 Jun 19]. Available from: https://bvsms.saude. gov.br/bvs/publicacoes/protocolo_notificacao_investigacao_ toxoplasmose_gestacional_congenita.pdf

43. Hotop A, Hlobil H, Gross U. Efficacy of rapid treatment initiation following primary Toxoplasma gondii infection during pregnancy. Clin Infec Dis. 2012;54:1545-52.
44. Avelino MM, Amaral WN, Rodrigues IM, Rassi AR, Gomes MB, Costa TL, et al. Congenital toxoplasmosis and prenatal care state programs. BMC Infec Dis. 2014;14:33.

45. Villard O, Cimon B, L'Ollivier C, Fricker-Hidalgo H, Godineau N, Houze S, et al. Serological diagnosis of Toxoplasma gondii infection: recommendations from the French National Reference Center for Toxoplasmosis. Diag Microbiol Infect Dis. 2016;84:22-33.

46. Peyron F, L'Ollivier C, Mandelbrot L, Wallon M, Piarroux R, Kieffer F, et al. Maternal and congenital toxoplasmosis: diagnosis and treatment recommendations of a French multidisciplinary working group. Pathogens. 2019;8:24. 